\title{
Editorial: \\ Canadian Association on Gerontology Policy Statement on Assistive Devices for Seniors
}

Statement of the Problem: Canada has no consistent policy on technology-related assistance for individuals with disabilities and/or physical limitations, or on financial assistance with the acquisition of such devices. Evidence suggests that financing is a major barrier to the use of assistive devices (LaPlante, Hendershot, \& Moss, 1997; Kozarevic \& Israel, 1987). This barrier has resulted in a lack of systematic reporting requirements for assistive devices services among direct-service programs, a lack of uniform classification of assistive devices expenditures, and blurred distinctions between assistive and mainstream technology (Mendelsohn, 1997).

Scope: Assistive devices include "any item, piece of equipment, or product system, whether acquired commercially off the shelf, modified, or customized, that is used to increase, maintain, or improve functional capabilities of individuals with disabilities" (U.S. Technology Related Assistance for Individuals with Disabilities Act of 1988, Tech Act, 29 USC Sec.2201). Categories of assistive devices used by seniors include those for mobility, personal care, home skills, and leisure activities (Axell \& Yasuda, 1993). There is insufficient evidence to support or refute the claim that assistive devices promote independence for seniors. However, it is known that assistive devices are commonly used by seniors; for example, nearly 35 per cent of Canadians 75 years and older use one or more devices, with vision aids being used by 90 per cent, and mobility and hearing aids increasing in use after 50 years of age to about 50 and 60 per cent respectively (Forbes, Hayward, \& Agwani, 1993).

Analysis of the Evidence: The fact that seniors who require assistive devices frequently either do not receive or do not use them suggests a lack of effectiveness in promoting seniors' independence through this means. Low education (Forbes et al., 1993), rural residence (Forbes et al., 1993; Kozarevic \& Israel, 1987), social isolation (Forbes et al., 1993), female gender (Forbes et al., 1993; Kozarevic \& Israel, 1987), membership in populations known to be underserved by systems for health and welfare (i.e., aboriginals and rural residents) (Galvin, 1997), and advanced age (Kozarevic \& Israel, 1987) are associated with non-use and/or under-use by those who require assistive devices. However, it is important to note

Canadian Journal on Aging / La Revue canadienne du vieillissement / Vol. 20 no. 1 2001, i-vi 
that evidence shows 79 per cent of all owned devices are reported to be used (Mann, Hurren, \& Tomita, 1993).

One major U.S. survey (National Council on Disability, 1993) has found that 80 per cent of older persons reported reduced dependence on others and approximately 50 per cent were able to avoid entering a nursing home as a consequence of using assistive devices. The one randomized controlled trial identified in the literature, a study of 22 elderly nursing home residents, identified that those who were equipped and trained to use a hand-held remote control for activating radio and light switches had three times the rate of radio use as did control subjects, suggesting enhanced exercise of independence (Mann, 1992).

Patterns of device use do not necessarily predict subjective perceptions of independence. However, insofar as self-reports of device ownership and frequency of use can be regarded as valid measures of assistive device use, assistive devices, particularly mobility devices, vision aids, and home accessibility devices and modifications, do appear to contribute to functional independence. Assistive device use by seniors is more likely if the devices are supported by service agencies (Mann et al., 1993).

Recommendations: The Canadian Association on Gerontology supports government adoption of a definition of assistive devices appropriate to the Canadian context and the development of consistent policies regarding financial support for seniors who may benefit from their use.

The Canadian Association on Gerontology encourages research funders and researchers to support and undertake rigorous evaluative research to test the effectiveness of the vast array of assistive devices available.

The Canadian Association on Gerontology recommends that positive gains might be achieved through an orientation where assistive devices are seen as supporting the goal of maximizing function and independence.

\section{References}

Axell, L.A., \& Yasuda, Y.L. (1993). Assistive devices and home modifications in geriatric rehabilitation. Geriatric Rehabilitation, 9, 803-821.

Forbes, W.F., Hayward, L.M., \& Agwani, N. (1993). Factors associated with self-reported use and non-use of assistive devices among impaired elderly residing in the community. Canadian Journal of Public Health, 84, 53-57.

Galvin, J.C. (1997). Consumerism and outreach to underrepresented populations. Technology and Disability, 6, 49-61.

Kozarevic, D.J., \& Israel, L. (1987). Disabilities and the level of affected activities of daily living. Revue Epidémiologique et Santé Publique, 35, 248-256.

LaPlante, M.P., Hendershot, G.E., \& Moss, A.J. (1997). The prevalence of need for assistive technology devices and home accessibility features. Technology and Disability, 6, 17-28.

Mann, W.C. (1992). Use of environmental control devices by elderly nursing home patients. Assistive Technology, 4, 60-65. 
Mann, W.C., Hurren, D., \& Tomita, M. (1993). Comparison of assistive device use and needs of home-based older persons with different impairments. The American Journal of Occupational Therapy, 47, 980-987.

Mendelsohn, S.B. (1997). Assistive technology: public policy and financing. Technology and Disability, 6, 29-48.

National Council on Disability. (1993). Study on the financing of assistive technology devices and services for individuals with disabilities. Washington, DC.

This position paper was prepared by Carol McWilliam, Ed.D., at the request of the Canadian Association on Gerontology. It was approved by the Board as an official policy statement of the CAG on October 26, 2000. The paper is based on "Care Delivery Approaches and Seniors' Independence" by C.L. McWilliam, W.L. Diehl-Jones, J. Jutai, and S. Tadrissi, (Canadian Journal on Aging (2000), 19 (suppl. 1), 101-124). 